\title{
Emotion episodes of Afrikaans-speaking employees in the workplace
}

\begin{tabular}{|c|c|}
\hline \multicolumn{2}{|c|}{$\begin{array}{l}\text { Authors: } \\
\text { Cara S. Jonker } \\
\text { Althea Van der Merwe }^{1}\end{array}$} \\
\hline \multicolumn{2}{|c|}{$\begin{array}{l}\text { Affiliations: } \\
\text { 'Workwell Research Unit, } \\
\text { Economic and Management } \\
\text { Sciences, North-West } \\
\text { University, Potchefstroom } \\
\text { Campus, South Africa }\end{array}$} \\
\hline \multicolumn{2}{|c|}{$\begin{array}{l}\text { Correspondence to: } \\
\text { Cara Jonker }\end{array}$} \\
\hline \multicolumn{2}{|c|}{$\begin{array}{l}\text { Email: } \\
\text { cara.jonker@nwu.ac.za }\end{array}$} \\
\hline \multicolumn{2}{|c|}{$\begin{array}{l}\text { Postal address: } \\
\text { Private Box X6001, } \\
\text { Potchefstroom 2520, } \\
\text { South Africa }\end{array}$} \\
\hline \multicolumn{2}{|c|}{$\begin{array}{l}\text { Dates: } \\
\text { Received: } 26 \text { Jul. } 2011 \\
\text { Accepted: } 04 \text { May } 2013 \\
\text { Published: } 22 \text { July } 2013\end{array}$} \\
\hline \multicolumn{2}{|c|}{$\begin{array}{l}\text { How to cite this article: } \\
\text { Jonker, C.S., \& Van der } \\
\text { Merwe, A. (2013). Emotion } \\
\text { episodes of Afrikaans- } \\
\text { speaking employees in the } \\
\text { workplace. SA Journal of } \\
\text { Industrial Psychology/SA } \\
\text { Tydskrif vir Bedryfsielkunde, } \\
\text { 39(1), Art. \#1006, } 12 \text { pages. } \\
\text { http://dx.doi.org/10.4102/ } \\
\text { sajip.v39i1.1006 }\end{array}$} \\
\hline \multicolumn{2}{|c|}{$\begin{array}{l}\text { Copyright: } \\
\text { (C) 2013. The Authors. } \\
\text { Licensee: AOSIS } \\
\text { OpenJournals. This work } \\
\text { is licensed under the } \\
\text { Creative Commons } \\
\text { Attribution License. }\end{array}$} \\
\hline \multicolumn{2}{|l|}{ Read online: } \\
\hline 口ifra & $\begin{array}{l}\text { Scan this QR } \\
\text { code with your } \\
\text { smart phone or } \\
\text { mobile device } \\
\text { to read online. }\end{array}$ \\
\hline
\end{tabular}

Orientation: Emotions must be investigated within the natural contexts in which they occur. It therefore becomes crucial to study episodes in the workplace.

Research purpose: The objective of this study was to determine the positive and negative emotion episodes and frequencies of working Afrikaans-speaking adults.

Motivation for the study: To date, no study has been conducted to determine emotion episodes amongst White Afrikaans-speaking working adults in South Africa. Gooty, Connelly, Griffith and Gupta also argue for research on emotions in the natural settings in which they occur - the workplace.

Research design, approach and method: A survey design with an availability sample was used. The participants $(N=179)$ consisted of White Afrikaans-speaking working adults. The Episode Grid was administered to capture the emotion episodes.

Main findings: The main emotion episodes reported on with positive content included goal achievement, receiving recognition and personal incidents. Emotion episodes with negative content included categories such as behaviour of work colleagues, acts of boss/superior/management and task requirements.

Practical and/or managerial implications: The findings are useful for managers who want to enhance the emotional quality of the work-life of employees. Changes could be made, for example, to practices of giving recognition within work environments and the clarification of task requirements. The knowledge on emotion episodes could be very useful in planning interventions.

Contribution and/or value-adding: The findings and results of this study provided insight into emotion episodes as events in the workplace can cause positive and negative workplace experiences. This information should be taken into consideration with regard to wellness and emotion measurement efforts.

\section{Introduction}

Individuals bring all of themselves to work, including their traits, moods and emotions. Emotions are part of the lives of all employees and organisational researchers have certainly recognised this (Bunk \& Magley, 2013). Miner, Glomb and Hulin (2005) state that emotions at work are an important component of job attitudes and an important predictor of organisational behaviour. Emotion experiences or episodes at work have an impact on job performance, decision-making, creativity, turnover, teamwork, negotiations and leadership (Gibson, 2006; Hill, 1992).

Emotion episodes at work (for example, feelings of frustration with non-performing colleagues and anger about irate customers and unsympathetic managers) are all contributing factors that cause emotion in the workplace. These emotion episodes have an influence on how employees are feeling both physically and emotionally (Dasborough, 2006; Gibson, 2006; Lord \& Kanfer, 2002). The features of an emotion episode are that:

1. They are coloured by a positive or negative feeling.

2. They are normally triggered by an interaction involving work and identity.

3. They have a beginning marked by the triggering of a feeling and end with a dissipation of that feeling.

4. They have the potential to recur more than once. (Morgen, Ludlow, O'Leary \& Clarke, 2010)

Researchers increasingly focus their attention; therefore, on emotion research in work settings (Bouckengooghe, Raja \& Butt, 2013; Gorgens-Ekermans \& Brand, 2012; Sacco, 2010). However, there is a lack in research studies that have examined in detail events at work that have an affective content. Bunk and Magley (2013) add to this argument and state that the frequency and valance (positivity and negativity) of emotion events at work need investigation. Morgen et al. 
(2010) point to this importance of investigating positive and negative events or episodes as dimensions of affective events in the workplace. The investigation of emotion episodes as perceived by employees will provide a more balanced and comprehensive picture than an investigation of a single emotion state (Bunk \& Magley, 2013).

The importance of research in the field of emotions can also be seen in the projects of The National Centre of Competence in Research, Affective Sciences (NCCR Affective Sciences) in Switzerland (http://www.affective-sciences.org). The NCCR Affective Sciences is one of the first research centres worldwide dedicated to the interdisciplinary study of emotions and their effects on human behaviour and society. One of their projects entails the investigation of emotion concepts across cultural groups of which South Africa forms part. Although different cultural groups form part of this study, the focus of this article will be to report on emotion episodes of Afrikaans-speaking working adults.

Little or no data on the context of emotion episodes amongst the White Afrikaans-speaking working adult group in South Africa exists. Although South Africa has eleven official languages, Afrikaans and English are still common languages in the industrial workplace. This stems from the apartheid years when these two languages were legislated as the two official language groups (Makhuba, 2005). Today, Afrikaans is the language that is spoken the second most in the majority of provinces in South Africa (http://www.southafrica.info) and the language group that is spoken the third most in South Africa overall. According to the findings of Census 2011, Afrikaans is also the language group that showed the most growth in percentage of language speakers (Census, 2011). Due to possible dialects in Afrikaans and the exploratory nature of the research, this study only focused on the White Afrikaans-speaking group.

\section{Problem statement}

\section{Background to the study}

Research regarding emotions at work include topics (but is not exclusive to) such as happiness (Ashkanasy, 2011), work-life balance (Westman, Brough \& Kalliath, 2009) and well-being (Chi \& Liang, 2013). However, Gooty, Gavin and Ashkanasy (2009) called for emotion researchers to investigate emotions within the natural contexts in which they occur - making an investigation into the emotion episodes in the workplace an important research topic. In addressing this issue, the Affective Events Theory of Weiss and Cropanzano (1996) can be applied.

The Affective Events Theory (AET) of Weiss and Cropanzano (1996) began to reshape the domain of organisation behaviour with the recognition of the emotion content attached to it. Miner et al. (2005) argue that the AET is one possible way of an organising framework for incorporating affect in the study of organisational behaviour. Little attention is paid to emotion episodes at work and how employees experience these events. The focus of investigating emotion episodes at work is unique to the AET. These events can range from minor events (receiving praise from a co-worker) to more extreme (being passed over for a promotion).

\section{Trends from the research literature}

According to the affective events theory (AET) (Weiss \& Cropanzano, 1996), the workplace is an environment in which certain conditions and happenings are experienced more positively or negatively by employees. Such experiences are referred to as 'affective events'. Belschak and Den Hartog (2009) mention an example of an event or emotion episode namely, performance feedback. These events trigger positive or negative emotions that influence behaviour and motivation at work (see Figure 1). Michel and Clark (2009) investigated the AET and conclude that, according to the AET, affect can be classified into positive affect (PA) and negative affect (NA). Positive affect is classified as a general tendency to be energetic, excited and joyful, whilst NA is characterised as a general tendency to be anxious, afraid and angry. Frijda's 1987 emotion theory states that affect is a subjective feeling state with a positive or negative hedonic tone.

Positive affect and negative affect are different but correlated dimensions. Sacco (2010) states that all human experiences (therefore also emotion episodes at work) can be derived as a combination of these to independent dimensions. The valence and arousal model of emotion (circumplex model) has a long history in affective psychology. Sacco (2010) states that although different dimensions of emotion have been reported, the circumplex model of emotion allows for a systematic arrangement of emotion experiences (see Figure 2).

Only a few studies have attempted to test components of the AET. Fisher (2000) used emotion terms generated by students to test their relevance to the workplace. The end result was a list with 16 emotion terms - eight positive terms and eight negative terms. The positive terms formed one factor and after investigation the negative terms formed one factor. Fisher (2002) states that positive and negative experiences operate separately in the brain; they operate largely independently and are activated by different stimuli.

\section{The potential value-add of this study}

The emotion episodes that employees experience must be investigated. Information on the emotion episodes in a specific cultural group can be used to develop emotion measurements, to plan specific interventions in the organisation and to manage those events specifically that have an affective content.

\section{Objective of the study}

The objective of this study was to determine different categories of emotion episodes in a specific cultural group. The research question formulated for this study was: 'What are the different categories of emotion episodes reported in the Afrikaans-speaking working adult language group in South Africa?'. 


\section{What will follow?}

Subsequently, an overview of the investigation of emotion episodes by means of the Affective Events Theory will be presented, followed by references to emotion episodes research. This will be followed by the research method, findings and the discussion of the categories of emotion episodes that Afrikaans-speaking employees experience.

\section{Overview of the literature}

Regarding affective psychology, the ground-breaking work conducted in the 1980s and early 1990s on emotional labour (Hochschild, 1983) and emotional intelligence (Salovey \& Mayer, 1990) indicates that studies on emotions in organisations became an important research topic. Although largely neglected for several decades, research investigating emotion in organisations has increased in organisational psychology (Bouckenooghe et al., 2013). National (Cilliers, 2012; Olckers, Buys \& Grobler, 2010; Jonker, Van der Merwe, Fontaine \& Mering, 2011; Koortzen \& Oosthuizen, 2012) and international (Fisher, Minbashian, Beckmann \& Wood, 2012; Lindenbaum \& Jordan, 2012; Michel \& Clark, 2009) publications since then (to name a few) on this subject have resulted in an understanding of the role of emotion constructs in organisational behaviour being available.

Recently, Gooty et al. (2009) called for emotion researchers to investigate emotions within the natural contexts in which they occur - making an investigation into the emotion episodes in the workplace context an important research topic. More specifically, Morgen et al., (2010) also argue for an investigation of positive and negative episodes as dimensions of affective episodes in the workplace. Bunk and Magley (2013) state that the frequency and valence (positivity and negativity) of emotion episodes at work need investigation. Emotion events and emotion episodes are interchangeable terms to be used, but for the purposes of reporting the data, emotion episodes will be used.

The AET is one possible way of an organising framework for incorporating affect in the study of organisational behaviour. Little attention is paid to events at work and how employees experience these events. The focus of emotion episodes at work is unique to the AET. These events can range from minor events (receiving praise from a co-worker) to more extreme (being passed over for a promotion). These events lead to positive and negative emotions with a pleasant or unpleasant hedonic tone (Bunk \& Magley, 2013).

Glaso, Vlie Holmdal and Einarsen (2011) conclude that this theory indicates what happens between work events and subsequent employee attitudes and behaviour by focusing on the role of personality and emotion. The theory provides a comprehensive account of the antecedents and consequences of the structure of emotion episodes at work (see Figure 1). The AET argues that employees' attitudes towards the environment follow a cognitive as well as an affective route. The affective route determines the occurrence of positive or negative work events.

This is in line with the basic emotion theory of Frijda (1988) that concludes that events that satisfy goals have a positive content and events that threaten the individual can lead to a negative experience. Positive affect and negative affect are different but correlated dimensions. Positive affect (PA) is classified as a general tendency to be energetic, excited and joyful, whilst negative affect (NA) is characterised as a general tendency to be anxious, afraid and angry. Affect refers to longer lasting positive or negative emotion experiences and is classified as a state affect (mood) and trait or dispositional affect (Gooty et al., 2010). The valence (positive and negative) of the emotional response is tied whether the encounter is likely harmful or not to the individual (Gooty et al., 2010).

Sacco (2010) states that all human experiences (therefore also emotion episodes at work) can be derived as a combination of these to independent dimensions. The valence and arousal model of emotion (circumplex model) has a long history in affective psychology (see Russell, 1980). Sacco (2010) further states that although different dimensions of emotion have been reported, the circumplex model of emotion allows for

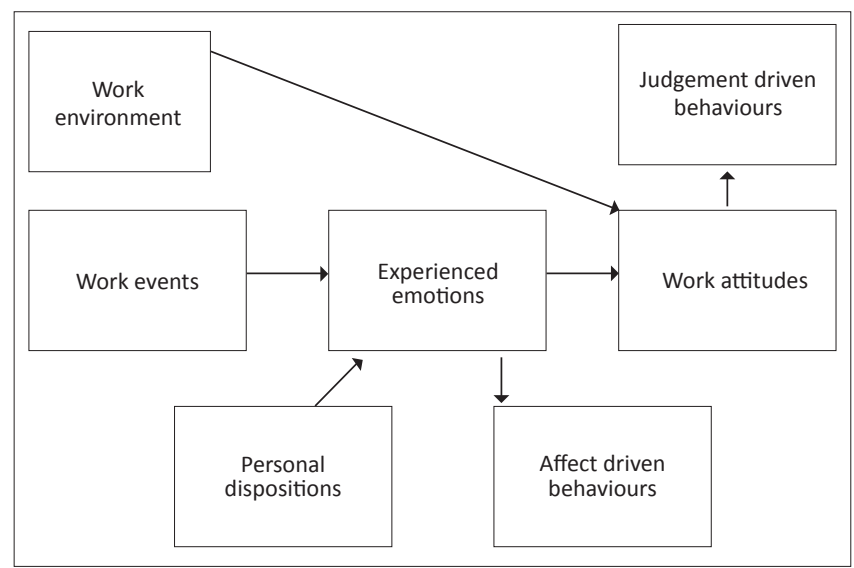

Source: Zerbe, W.J. (2008), Chapter 5: Feelings about ethical decisions: the emotions of moral residue, In W.J. Zerbe, C.E.J. Härtel \& N.M. Ashkanasy (Eds.), Emotions, Ethics and DecisionMaking (Research on Emotion in Organizations, Vol 4 (pp. 109-129). Bingley: Emerald Group Publishing Limited. http://dx.doi.org/10.1016/S1746-9791(08)04005-4

FIGURE 1: Weiss and Cropanzano's Affective Events Theory.

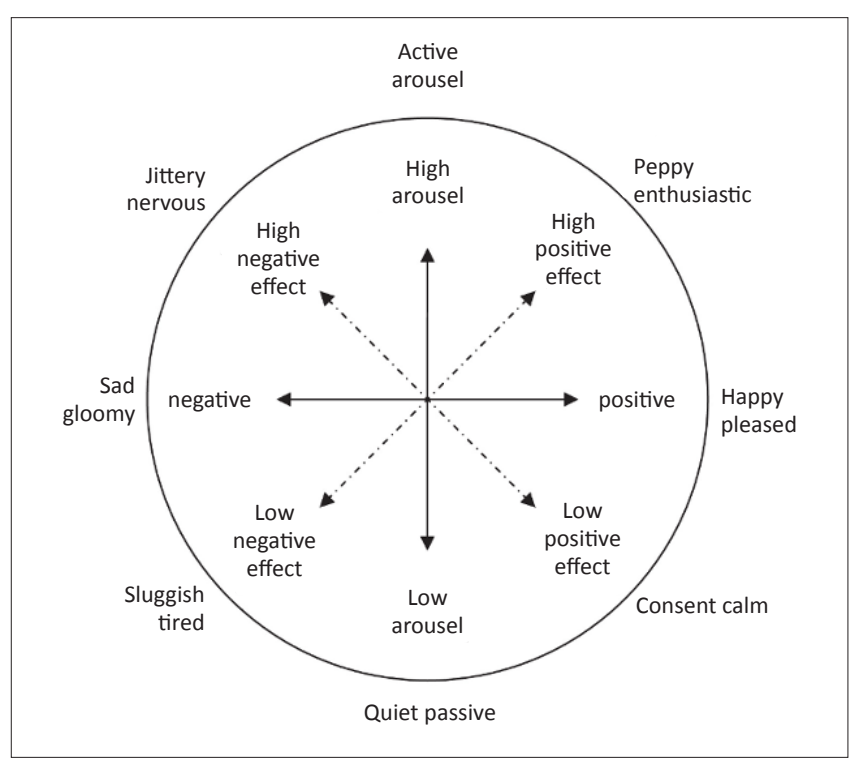

Source: Russell, J.A. (1980). A circumplex model of affect. Journal of Personality and Socia Psychology, 39, 1161-1178.

FIGURE 2: Circumplex model of emotion. 
a systematic arrangement of emotion experiences and a shared view of pleasant and unpleasantness (see Figure 2). Meeusen, Van Dam, Van Zundert and Knape (2010) therefore classify the emotion episodes as positive and negative events in their research. According to the circumplex model, the essence of the AET in providing a framework of events to be classified in positive and negative events, and an investigation of how studies in the past were conducted (Meeusen, et al., 2010), the present study classified emotion experiences as positive and negative emotion episodes.

Meeusen et al. (2010) states that emotions are triggered by actual events in the workplace, and should; therefore, be more readily recalled than vague and diffuse moods whilst at work. The emotion process begins with an event, which is evaluated by importance and relevance to well-being. This explains why the same event can trigger different emotions in different people. Lam and Cheng (2012) state that emotion episodes shape the intensity of the person's subjective emotion reaction. They point out that work features can shape regular work events in the workplace. For example, a stable work environment can influence affective events, which then determine affective states and work attitudes.

According to Miner et al. (2005), the theory on emotions at work is an important component of job attitude and an important predictor of organisational behaviours. Li, Ahlstrom and Ashkanasy (2010) conclude from the AET that it assumes continuing recurrence of emotion episodes and that this type of research is also consistent with a narrative approach. The Critical Incident Technique (CIT) was chosen to be used in the investigation (this will be explained in more detail in the methodology section). Subsequently, some examples of the application of the AET and consequent emotion episodes will be presented.

In 1998, Basch and Fisher investigated the causes of workplace emotions of employees of an Australian hotel, and focused on the emotion events in the workplace. Basch and Fisher (1998) investigated specific events within an employee's day-to-day set of activities and sought to understand which of these events led to certain emotional reactions. Workers were presented with ten emotions and asked to describe a work event that caused them to experience each of the given emotions. They divided the positive emotion events and the negative emotion events and named the types of events experienced. In the first categories, fourteen job events with positive emotion episodes were reported with examples such as acts of work colleagues, acts of management, goal achievement, receiving recognition, acts of customers, involvement in challenging tasks and interacting with customers (Basch \& Fisher, 1998).

In the second set of categories, thirteen job events with negative emotions episodes were reported, with examples such as personal problems, workload, physical situation, external environment, company policies, lack of influence and control, and making mistakes. With regard to experiencing negative emotions, workers were more likely to cite events related to dealing with people than events related to dealing with things (Basch \& Fisher, 2000).

In the late 1950s, Herzberg, Mausner and Snyderman (1959) asked respondents to tell them about a time that they felt especially good or bad about their job. The events were subsequently sorted into 16 categories. Some of these categories included episodes where respondents felt exceptionally good about their jobs, for example achievement, recognition, the work itself, responsibility, and advancement or growth. Other categories included episodes where people felt particularly bad about their job, such as problems with supervisors, company policy, compensation and working conditions. In both mentioned studies, one might expect that different kinds of events would cause different emotions whilst working; therefore, Izard (1991) state that research on emotion are quite clear that different types of events cause different emotions. Although the AET is unique in its explanation that events at work determine emotion, it does not provide examples of such events.

Haag (2005) acknowledges that the amount of interaction workers have with other people at work seems to be a strong determining factor in the extent to which that workers experience negative or positive emotions related to their job. That is why Weiss and Cropanzano (1996) say that when events happen to people in work settings, people often react emotionally to these events. The emotions experienced during an emotion episode are related and can; therefore, be correlated with factors such as job satisfaction, organisational commitment and intention to quit (Basch \& Fisher, 1998). By saying this, Basch and Fisher (1998) provide an example: an enriched job might more often lead to discrete events involving feedback, task accomplishment and optimal challenge, which may then lead to positive emotions such as pride, happiness and enthusiasm. In the study conducted by Basch and Fisher in 1998, the question was asked: 'What job events or situations cause employees to experience specific emotions while at work?' For this reason, one has to understand the concept of 'emotion episodes', because emotion is involved in such episodes.

In conclusion, the investigation of emotion episodes as perceived by employees will provide a more balanced and comprehensive picture than an investigation of a single emotion state (Bunk \& Magley, 2013). Wegge, Van Dick, Fisher, West and Dawson (2006) state that there is a lack in research studies that have examined in detail which features at work have an affective content. The AET does not specify which events have positively or negatively perceived content. Scherer (2009) argues that emotion episodes as a whole and the components are often under-researched. Kafetsios and Zampetakis (2008) state that work affect is an important aspect of work experiences. Kahnemann, Kreuger, Schkade, Schwartz and Stone (2004) argue that the investigation of episodes within the contexts in which they occur has a greater claim to validity and is less subject to bias than the data from the more traditional questionnaire or open-ended interview. 


\section{Research design Research approach}

A mixed-method approach was utilised in this study. A crosssectional field survey design was used to gather information on the emotion episodes. A qualitative approach was utilised for the coding and categorisation of written emotion episodes. A quantitative approach was used to assess the nature and frequency of emotion episodes.

\section{Research method Participants}

This study made use of an availability sample of $(N=179)$ of White Afrikaans-speaking working adults between 18 years and 70 years. The minimum educational level for inclusion was Grade 12. The participants' first language was Afrikaans. The majority of participants who made themselves available as part of the study population were from the Eastern Cape, Free State and North West Provinces of South Africa. A wide variety of occupations was covered in the study and each of the participants participated on an anonymous basis.

In total, 179 White Afrikaans-speaking working adults participated in this study. The participants completed a translated version (Afrikaans) of the Emotion Episode Questionnaire. The ethnicity of the group was White participants. In terms of gender, the women outnumbered the men by two to one [women: $73 \%(n=130)$ and men: $27 \%$ $(n=49)]$. Twenty percent $(20 \%)$ of the group were between the ages of 18 and 29 years, whilst $80 \%$ were 30 years of age and older. The largest part of the participants was from the Eastern Cape Province (81\%). The majority (45\%) of the participants had a Grade 12 education level, whilst 55\% of the participants had other tertiary levels of education (ranging between a one-year diploma and post-graduate qualifications). The wide variety of occupations that was covered in this study included teachers, police officers, clerks, financial advisors, engineers, marketing advisors, doctors, bookkeepers, hairdressers, accountants, panel beaters, psychologists, bankers, nurses and estate agents.

\section{Measurement instrument}

The Episode Grid was developed as part of an Emotion Research Project at Ghent University in Belgium as part of an initiative of the International Society for Cross-Cultural Research on Affect that falls under the Swiss Affect Sciences Centre. Participants were asked to reflect on the last two most intense emotion episodes experienced at work. Questions in the Episode Grid are formulated in such a way as to capture and aid the emotion episode as vividly as possible. Example questions include: 'Please describe the emotional episode: What happened?; Who was involved?; How did the situation begin?; How did it evolve? and How did it end?'.

\section{Research procedure}

The study was approved by an ethics committee from a tertiary education institution in South Africa. Participation was voluntary and confidentiality and anonymity were ensured. Because of the sensitiveness that may occur when describing emotion episodes, the study was thoroughly explained to each participant prior to data collection. A letter explaining the objective of the study was also distributed to each participant with details of wellness centres attached, if needed. Completed questionnaires were gathered in person by the researchers and placed in a sealed box.

\section{Data analysis}

The incident classification system suggested by Bitner, Booms and Tetreault (1990) was adopted to develop a preliminary classification scheme. The episodes were sorted and reclassified until a meaningful set of categories were derived from the data. Data from the respondents were sorted into categories by an industrial psychology researcher and was reviewed by another psychologist. These categories were given to another industrial psychologist with a good track record of qualitative methods to classify these categories as a reliability or credibility check according to the category scheme. An inter-coder reliability measure suggested by Miles and Huberman (1994), the number of agreements or total number of agreements plus disagreements, was used to calculate the agreement between the two coders and the researchers.

\section{Findings}

Table 1 presents the results of the categories of emotion episodes for positive and negative emotion episodes. Nine categories emerged for positive emotion episodes, with a total of 84 emotion episodes reported. Negative emotion episodes were reported 267 times within 19 different categories of emotion episodes. Examples of reported episodes are reported in Box 1 and Box 2. Only eight categories were categorised differently than the original coders and; therefore, a reliability or credibility overlap of $97 \%$ was achieved, which is far more than the recommended 70\% overlap suggested by Miles and Huberman (1994).

In Table 1, 179 respondents reported 84 satisfying and 267 negative emotion episodes that took place at work. Seven (7) out of the 358 emotion episodes were unclassifiable. Only eight categories were not categorised by the independent coders and an overlap of more than $90 \%$ was achieved.

Each participant reported two (2) emotion episodes. Using the essence of the AET as described in the literature study, these episodes were classified on positive and negative content. Nine categories of positive emotion episodes emerged (Table 1 and Box 1) and nineteen categories of negatively experienced emotion episodes emerged (Figure 2 and Box 2). In terms of the categories of positively and negatively experienced episodes, negatively experienced emotion episodes outnumbered positive emotion episodes by three to one. The numbers in brackets in Table 1 are the frequency of co-occurring reported emotion episodes. 
TABLE 1a: Categories of emotion episodes experienced with a positive content $(N=358)$.

\begin{tabular}{lll}
\hline Positive content & $\boldsymbol{N}$ & $\mathbf{\%}$ \\
\hline Goal achievement & $(31)$ & 90 \\
Receiving recognition & $(20)$ & 5.0 \\
Personal incidents & $(10)$ & 3.0 \\
Behaviour of work colleagues & $(08)$ & 2.0 \\
Task recognition & $(06)$ & 2.0 \\
Acts of boss/superior/management & $(04)$ & 1.0 \\
Emotion involvement & $(03)$ & 1.0 \\
Workplace policy & $(01)$ & 0.2 \\
Subordinate behaviour & $(01)$ & 0.2 \\
\hline Total & $\mathbf{8 4}$ & $\mathbf{2 3 \%}$ \\
\hline
\end{tabular}

Seven ( $2 \%$ ) out of the 358 emotion episodes reported in the workplace were unclassifiable.

TABLE 1b: Categories of emotion episodes experienced with a negative content $(N=358)$.

\begin{tabular}{lll}
\hline Negative content & $N$ & $\%$ \\
\hline Behaviour of work colleagues & $(58)$ & 16.2 \\
Acts of boss/superior/management & $(47)$ & 13.10 \\
Task requirement & $(33)$ & 09.20 \\
\hline Personal incidents & $(26)$ & 07.20 \\
Subordinate behaviour & $(17)$ & 05.00 \\
Emotional involvement & $(15)$ & 4.200 \\
Work mistakes & $(13)$ & 0.400 \\
Customer behaviour & $(13)$ & 0.400 \\
Workplace policy & $(08)$ & 2.200 \\
Workload & $(08)$ & 2.200 \\
Lack of control & $(08)$ & 2.200 \\
Involved in disciplinary action & $(08)$ & 2.200 \\
Workplace strikes & $(04)$ & 1.100 \\
Lack of goal achievement & $(03)$ & 01.00 \\
\hline External environment & $(02)$ & 0.500 \\
\hline Physical well-being & $(02)$ & 0.500 \\
Lack of receiving recognition & $(01)$ & 0.200 \\
Wellness of colleagues & $(01)$ & 0.200 \\
Unfairness in the workplace & $(01)$ & 0.200 \\
\hline Total & $\mathbf{2 6 7}$ & $\mathbf{7 5 \%}$ \\
\hline Seven & & \\
\hline
\end{tabular}

Seven $(2 \%)$ out of the 358 emotion episodes reported in the workplace were unclassifiable.

\section{Categories of emotion episodes experienced with a positive content}

The highest category of positive emotion episodes experienced was Goal achievement, with 31 emotion episodes reported. Goal achievement describes situations where jobrelated targets or goals are successfully arrived at and are acknowledged with pride; therefore, when targets or goals are reached by people, very positive emotions will surround the work situation as well as any social event. The second highest reported episode in the positive category was receiving recognition, with 20 emotion episodes at work. This category refers to appraised behaviour towards employees or colleagues for goals achieved or helping behaviour. The third highest category reported was personal incidents, with 10 emotion episodes. This reflects one's own positive experiences that were of a personal nature and not work related, although the emotion of the episodes was carried over to the work situation.

Behaviour of work colleagues is behaviour towards oneself, an employee, colleagues or management. Task recognition is appraised behaviour towards an employee, colleagues or management for a job well done. Acts of boss or superior or management is recognition through acts or gestures from the boss or superior or management indicating approval and was reported four times. Emotion involvement was reported three times and involves recognition of emotions of pride, satisfaction, and ownership of the employee by management. Workplace policy, involves procedures instituted to provide positive outcomes for employees, and Subordinate behaviour are acts of defiance and a subversive nature undermining the authority of management and enhances the employee's ego; these were only mentioned once and were reported the least number of times.

Examples of the reported emotion episodes with a positive content are reported in Box 1. Five examples are reported per emotion episode. In cases where fewer than five episodes were reported, all the episodes are reported.

\section{Categories of emotion episodes experienced with a negative content}

In the categories of negative emotion episodes (Table 1b), 58 emotion episodes were reported as Behaviour of work colleagues and those are behaviour towards the employee or a colleague of a less satisfying manner; most of these emotion episodes were relationship orientated. The participants reported 47 episodes of acts of boss or superior or management and those involved acts showing disregard for employee emotions and feelings. Task requirement, where an employee is required to perform undesirable tasks, was reported 33 times. These categories suggest less satisfying behaviour towards oneself or others by work colleagues, managers, supervisors and customers.

Personal incidents was mentioned 26 times and refers to less satisfying personal experiences that were of a personal nature and not work related, although the emotion of the episodes was carried over to the work situation. Subordinate behaviour is acts of defiance and a subversive nature undermining the employee and enhances management's power, and was reported 17 times. Emotional involvement is classified as a category where the employee becomes emotionally involved. 'Work mistakes' is feelings of apprehension, guilt and anxiety as a result of making a mistake at work, and it was reported 13 times. Customer behaviour refers to disrespectful and intimidating customer behaviour.

Workplace policy involves disagreement with management's rules and policy that impacts negatively on the employee. Workload involves overload of work for unrelated pay or too much work for the staff complement. Lack of control involves no set structure being in place, so that limitations and boundaries are undefined. Involved in disciplinary action involves resentment towards management for action taken against employees. All four categories were reported eight times in the present study. Workplace strikes is disruptive staff action, reported four times. Three episodes 
BOX 1: Examples of reported emotion episodes with a positive content.

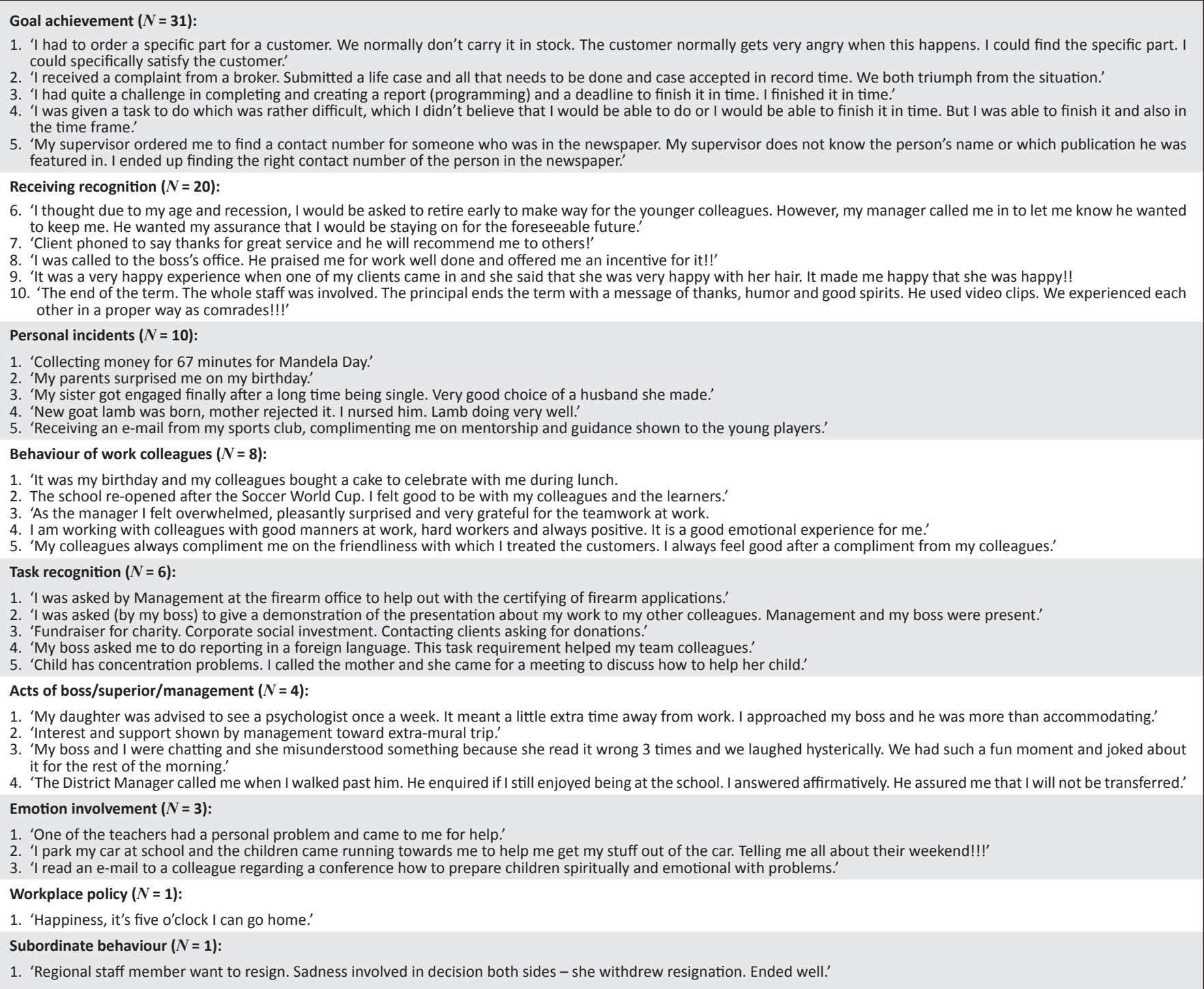

In total, $23 \%$ of all stories told $(N=358)$ were responses of satisfying emotion episodes in the workplace.

of lack of goal achievements were reported and it involves nonachievement of set goals resulting in employer action. Two emotion episodes were experienced that involve external circumstances impacting on the job and are categorised as external environment. Physical well-being emotion episodes were also reported twice and those are injuries caused by lack of adequate equipment or protection.

The next three categories were reported by each participant only once. Those are lack of receiving recognition, which involves apathy of management towards goals achieved, wellness of colleagues, which involves fear for co-workers' safety and emotional well-being, and unfairness in the workplace, which involves the inconsistent application of rules and regulations.

Examples of the reported emotion episodes with a negative content are reported in Table 3. Five examples are reported per emotion episode. In cases where fewer than five episodes were reported, all the episodes are reported.

\section{Discussion \\ Categories of emotion episodes with a positive content}

In total, 358 emotion episodes were reported, of which 84 were positive emotion episodes mentioned by the participants. Goal achievement, receiving recognition and personal incidents were reported as the most positive emotion episodes at work. Workplace policy and sub-ordinal behaviour were reported as the positive emotion episodes with the lowest frequency that White Afrikaans-speaking working adults experienced at work.

Goal achievement describes situations where job-related targets or goals were met (Basch \& Fisher, 1998), and recognition gained for that achievement, producing abundant and very satisfying emotions that result in self-actualisation and satisfaction. Goal achievement refers to the purposes or reasons an individual pursues an achievement task, most often operationalised in terms of academic learning tasks, although they can be applied to other achievement contexts such as athletic or business settings (Pintrich \& Schunk, 1996). 
BOX 2: Examples of reported emotion episodes with a negative content.

Behaviour of work colleagues $(\boldsymbol{N}=\mathbf{5 8})$ :
1. 'Attended a progress meeting at which a group of engineers represented the company. Many were unprepared and the meeting went very badly, took far too long and
nothing much was achieved that day at the meeting. I got totally irritated!'

2. 'I have my own office at work. New member started with no office space available. Other members want me to give up my office and share an office with someone else, I refused!

3. 'Pupils had to be kept busy. Volunteers asked. Felt irritated because once more only the same group of people was prepared to help out!! The other sat back and kept quiet. " had to go and visit my husband in hospital, but before I can go I have to find somebody to take my place at the switchboard. All of a sudden everyone is too busy to help

out. I was very upset about my colleague's behaviour. I have no other option to put all calls through to the CSC at the police station."

5. 'I was accused of having affairs with certain men at the workplace. Most of my colleagues got involved and spread the stories.'

Acts of boss/superior/management $(N=47)$ :

1. 'In finishing, in my opinion, a very important report, I wanted to talk it through with my boss and some colleagues before forwarding it. The meeting did start late; there wasn't big interest from the others. I could tell everything I wanted, as my boss preferred to go home. The feedback was "yes, yes it's okay, sent it on".

2. 'A senior member accused me of throwing away an important document and accused me of being a liar. After the fight, the document was found on her table.'

3. 'My area manager promised me a job as an assistant manager but she changed her mind about it. I was very upset and she hurt me very much. IT IS NOT RIGHT!!'

4. 'My boss was upset that I was not booking my time according to what he wanted and threatened to fire me. I was fearful that he would follow through, now I have lost interest in my work.'

5. 'At my performance appraisal meeting, it started off very well with my manager giving high marks. Head Office reduced my marks with no reason. Head Office does not answer my calls or enquiries about this.'

Task requirement $(N=33)$ :

1. 'I am in charge of regulating and checking telephone accounts. I do daily limit checks and when a member goes over his/her weekly limit, they are informed. I informed a member and he became agitated that I told him to slow down on his usage of outgoing calls with his phone.'

2. 'I was busy with the English literature period with a Gr.11 class. Learners were disruptive and uncooperative. Although I asked for silence several times, a few learners continued mumbling. I was furious - raised my voice, threatening that nobody, not even the prefects, would be exempted from being chased out of the class if they don't listen.'

3. 'It was my day off. I was called in to work, due to short staffing. Result: disappointment, anger and demotivated.'

4. 'Visited a murder scene, three people burned to death. Had to assist on the scene. 2 years after the incident I was off sick with PTSD and I am still not ok.'

5. 'I was "accused" by a Grade 12 learner that marks given (by me) for a project was "too low", compared to the marks given by other teachers for the same task or project.' Personal incidents $(N=26)$ :

1. 'I was looking for accommodation, because of my family situation that I was going through together with my children. No one could help me, not even the station commander. It is not resolved, I am still struggling!'

2. 'I had a argument with my ex-husband, started at home the previous evening. I was very upset at work, I struggled to work. I spoke to my psychologist and felt better afterwards, but the problems are still there.'

3. 'A teacher asked my son to go and call a Gr. 9 learner. He came back and said she was not in class. Eventually she said he lied since she was in class, but not at the moment he was there. It upset me when my son was telling me the story.'

4. 'I had accidentally dropped an expensive bottle of perfume at work and it broke. I have to pay for it!'

5. 'One of my friends at work committed suicide. He shot himself and left his wife and 2 boys behind. The youngest boy has a paraplegic condition. I am sad at work.'

Subordinale behaviour $(N=17)$ :

1. 'A subordinate was told to do something and became uptight and cheeky. I just told her what to do. Made sure she understands and walked away. She answered back and it wasn't necessary as it was a single instruction. I told this is what you will do and that is it. She did it and now resents me.'

2. 'My subordinate didn't report a meeting in time. It caused lots of problems (thereafter, I tried to educate him on why it is important to be on time and act professionally).'

3. 'Employee went behind my back to state that she is not happy with midyear review. But when I asked her, she said she was happy. It caused problems, and had a meeting to talk about the unhappiness.

4. 'Irritation with co-worker due to poor work etiquette (myself and the receptionist). Fist thing in the morning, she go onto the internet (Facebook) instead of working. I reprimanded her.'

5. 'I wanted to go home as I had far to travel. My assistant was delaying me. My assistant kept asking me questions and asked for my help on task that I had assigned to him. This forced me to stay on longer. Eventually I left and told him to deal with it himself and take some responsibility for his own work. I left and the work was never completed. Emotional involvement $(N=15)$ :

1. 'A child in my class told me her father hits them, I was sad and furious that incidents like this take place.'

2. 'I consulted a client being diagnosed with terminal illness and query information on treatment. Involved basically but felt great sympathy for client and administration for their acceptance of the situation.'

3. 'Client came in who had just lost her father and it was the day of the funeral. She was very tearful and we all went to hug her and her mom. I was very tearful thereafter but all of us at work gave her a lot of love and understanding.'

4. 'When I found out one of my clients mother died, she was very emotional and that made me said, but after I consoled her she felt better.'

5. 'A death, a client of mine had a heart attack. Very, very sad about the loss, lots of tears and sad faces, since this client was familiar to everyone and was more a friend as a client.'

\section{Work mistakes $(N=13)$ :}

1. 'A headcount target in January was found to be incorrect yesterday. Finance Section was involved at boardroom level. End with a short discussion with team.'

2. 'My Finance Manger told me that my work did not balance. I was involved in the situation on my own. My financial month-end is to be finalized for the financial meeting. Ended well the Financial Manger assisted me.'

3. 'I was involved in an argument with one of my colleagues. He complained that I lost one of his documents that I had to type. I denied it at first but eventually found it in my draw and I ended up apologizing to him.

4. 'There was an inspection involving inspectors from Head Office. There was a mistake when counting money in the safe which was later resolved.'

5. "Documents were not filed properly, but left discarded in a box. Much time was wasted searching for the information. The "responsible" person was not around to help resolve the situation.'

Customer behaviour $(N=13)$ :

1. 'Customer had a bad attitude from beginning - the glass he ordered never arrived as promised. Made him even more mad - I felt sad, very scared and emotional - when the glass arrived I felt relieved and the customer happy.'

2. 'A 3rd letter arrive a week and a half later, from the same firm, accusing me of the same incompetence and indolence towards my work.'

3. 'I could not give client what he wanted when he wanted it. Client unhappy and impatient. Bad / unresolved.'

4. 'A Friday afternoon a parent visited my class. He was angry about a letter in his child's homework book. He didn't greet me and just started screaming at me.'

5. 'A client phoned to say that PG Glass fitted the wrong windscreen to her Merc 300 SCK. She is very unhappy. I reported it to head of claims and they are sorting it out.'

Workplace policy $(N=8)$ :

1. 'Boss insisted we wear ties and jackets. He thinks it will improve productivity. We had to comply to the instruction without any say in the matter.'

2. 'I am entering into contract work and my company does not want to pay me what I want per hour.

3. The company I worked for restructured and the work I'm doing was centralized. They suddenly told me they are centralizing and did not tell me why. I was not part of the decision I was just told via e-mail. I did not even expect it I was very shocked and disappointed.'

4. 'In 1982 four of us were merit rated and became supervisors. In 1989 nine supervisors were appointed without merit rating on the same salary scale. All the staff was not divided under 13 supervisors. Four of us had 8 staff members under our supervision. In 1991 we were again divided back into working units and not supervisors.'

5. 'I wanted to take leave for 3 days and the commander didn't want to approve my leave because it was during the Soccer time. At the end after explaining, I got my leave.'

Workload $(N=8)$ :

1. 'I was reprimanded for not having my typing work done in time. I was called into the boss's office and warned to work faster.'

2. 'I was working under a lot of stress, receiving more dockets than I could attend to without the necessary resources.'

3. 'Problem came up and I was involved very late in this topic. I gave the max input, but it was not enough time to give feedback to my boss. Next evening my boss was very disappointed.'

4. 'Argument with my boss. There is too much general admin work, which take up too much time, resulting in the core functions being not performed. At the end of the day they want results. Time for actual work is not there anymore. It ended in frustration.'

5. 'I have to finish a report for my work on my own. There is inspection the next day. Too much to do in a short period of time. Finished everything.' 
BOX 2 (Continues...): Examples of reported emotion episodes with a negative content

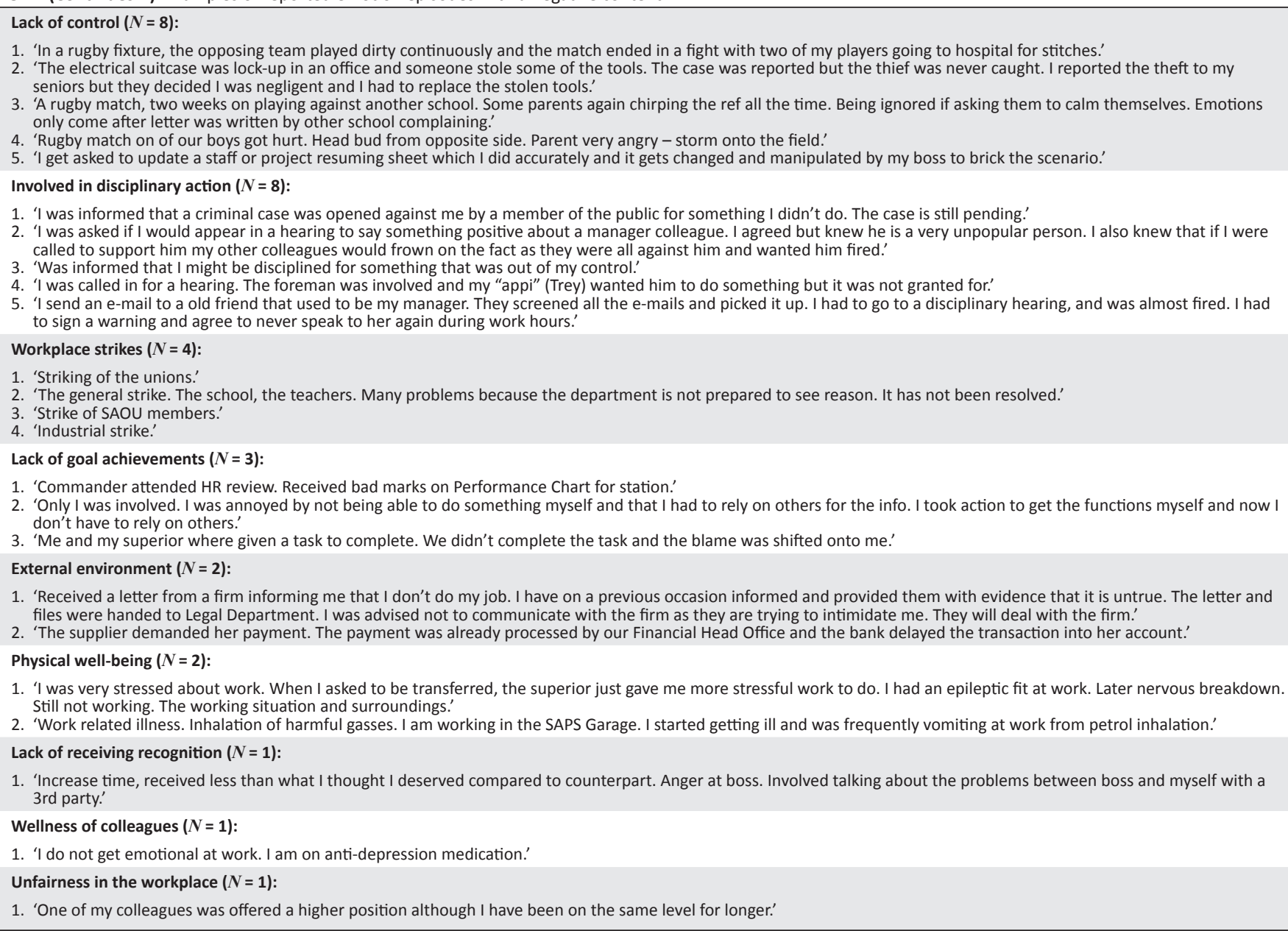

In total, $75 \%$ of all stories told $(N=358$ ) were responses of negative emotion episodes reported.

Basch and Fisher (1998) state that receiving recognition refers to satisfying feedback from managers, supervisors and work colleagues on meeting targets or performing a job to a high standard, or receiving a 'pat on the back' for good performance or helpful behaviour. When receiving recognition at work, people feel more accepted and respected by colleagues; and accordingly recognition and reward are accompanied on a social level with social elevation when interacting with colleagues. Half (1994) mentions that an amount of recognition is relative to job satisfaction. Bialopotocki (2007) conceptualises recognition as an event that occurs when employees perceive that they are being praised for a job well done. According to Blasé and Kirby (1992), receiving recognition leads to increased motivation, increased loyalty, and increased production to achieve expectations of one's boss and increased use of positive discipline strategies.

Personal incidents reflect an individual's reaction towards his or her work or colleagues on satisfying emotional episodes that occur in his or her life. Maslow states clearly that employment allows people to become self-actualised (Maslow \& Lowery, 1998); therefore, it is the hierarchy of needs for the individual in a workplace that counts. Positive emotion episodes at work have a direct satisfying influence on an individual's behaviour and attitude at work and affect work performance. In turn, this may lead to recognition, reward and ultimately a stable environment within the workplace resulting in uplifting of satisfaction and/or quality of life (Haag, 2005).

Barnett and Hyde (2001) explain that work and the workplace (i.e. job role quality) can potentially enhance family wellbeing and positive aspects of family life (i.e. family role quality) can spill over into the workplace. Studies done in 2006 that focused on White professional workers have supported the view that work-family experiences affect physical health. Greenhaus, Allen and Spector (2006) state that apart from conflict and positive spill over, physical health and emotional reactions to combining work and family roles are also a crucial outcome of interest. Higher positive spill over between work and family has been associated with better self-appraised health (Grzywacz, 2000).

Malik, Saif, Gomez, Khan and Hussain (2010) found that social support is moderately related to employee performance and job satisfaction and has a weak relationship with work-family balance, whereas employee performance is moderately related to job satisfaction. The hypothesis can thus be formulated that positively experienced emotion episodes in the workplace can be strongly associated with 
salary, occupational stress, empowerment, company and administrative policy, achievement, personal growth, relationship with others, and the overall working condition. It has been argued that an increase in positive affect can influence job satisfaction that can increase worker productivity (Shikdar \& Das, 2003; Wright \& Cropanzano, 1997).

The mentioned positive emotion episodes with the highest frequency (goal achievement, receiving recognition and personal incidents) all occurred on an individual level. These episodes may also point to the importance of a meaningful work-life for the employee. Goal achievement and receiving recognition may be perceived by the employee as critical factors in perceived career success. It clearly points to motivational factors and the importance of feedback regarding performance. These events also provide information on episodes that can possibly contribute to work engagement. An enhancement of the experience of these episodes may also foster job satisfaction and enhance the selfconfidence of employees.

\section{Categories of episodes for negative emotions experienced}

In total, 267 negative experienced emotion episodes were reported. Behaviour of work colleagues, acts of boss or superior or management and task requirement were the highest reported negative emotion episodes. Lack of receiving achievement, wellness of colleagues and unfairness in the workplace were reported as the episodes with the lowest frequency.

Haag (2005) mentions that emotion episodes related to people would be more negative to people in general than events related to things at work. Behaviour of work colleagues was reported most in this sample group. Negative emotion episodes occur more often when people feel particularly bad about their jobs; problems with colleagues or the boss and frequent daily hassles will, for example, lead to a 'not so good' quality of life or lack of well-being.

The emotion episode acts of boss or superior or management was reported the second most. If negative behaviour from one's manager and colleague occurs at work, the employee's well-being will suffer and in turn this will affect work performance. Acts of colleagues and acts of management could account for $59 \%$ of instances in which employees experienced negative emotion episodes and are likely to contribute to the experience of negative workplace emotions (Basch \& Fisher, 2000).

When looking at the third highest episode, task requirement, it may lead to an individual feeling especially bad about his or her job and could result in a tendency to avoid social events. Laplante (2009) states that task requirements are determined by the boss or customer; therefore, by analysing the task requirements, it determines whether the stated requirements are clear or unclear, complete or incomplete. Task requirement also relates to job demands in the workplace. Jones and Bright (2001) state that job demands represent the psychological stressors in the workplace. These include factors such as interruption, time pressures, conflicting demands, reaction time required, pace of work, proportion of work performed under pressure, amount of work, degree of concentration required, and the slowing down of work caused by the need to wait for others.

The negative episodes with the highest frequency (behaviour of work colleagues, acts of boss or superior or management and task requirement) suggest that a leading cause of perceived negativity is interactions with other employees. These episodes point to factors that are inherent in the workplace. It indicates that relationships at work are seen as factors that can influence job satisfaction. The role that social support plays in emotion experiences should be regarded as important. It also becomes important to consider workplace features as predictors of the experience of negative emotion episodes.

\section{Limitations}

The participants experienced difficulty in providing two (2) emotional episodes that took place in the workplace. The nature of the questionnaire was very time consuming and some of the participants indicated that they were not fully familiar with the vocabulary of the emotion terms used in the questionnaire regarding the emotion episodes. Many of the participants reported that this was the first time they had completed such a questionnaire in general, and in particular a questionnaire based on emotions, but they really enjoyed it. This research made use of availability sampling, which could have influenced frequencies obtained of emotion episodes. One can argue that people who experienced a negative emotion episode had a greater motivation to participate. The critical incidents were self-reported experiences and the role of emotion regulation and management was not accounted for. The study only focused on one cultural group in the population and not all provinces were included in the research. During the time of this data collection, strikes by workers and problems with transport were experienced in South Africa. This could have led to the high reported rate of negative emotion episodes at work and can be seen as a limitation in the present study.

\section{Conclusions and recommendations}

Firstly, it would be interesting to determine which emotions and action tendencies are linked to the more positive episodes and which are linked to negative episodes. The second suggestion is to investigate which emotion episodes relate more to female and which more to male workers, thirdly to determine whether the age group, gender or marital status play a role in the number of negative emotion episodes experienced in the workplace. Fourthly, which organisations and occupations experience more satisfying episodes and which negative emotion episodes, and lastly, correlations with individual differences (such as emotional intelligence) and organisational constructs (such as job satisfaction and organisation commitment) can be determined. 
The results clearly indicate that goal achievement, receiving recognition and personal incidents were the most reported within the positive content emotion episodes category. The end result of the first two categories is job satisfaction. Job satisfaction has a major effect on people's lives and can benefit in various ways, such as one's physical health, mental health and social life and the roll-over to life satisfaction. Indirectly, job satisfaction benefits the organisation, because satisfied workers will be much more productive, it will affect absenteeism for the better, employees will perform better at work, and they will be retained within the organisation for a longer period.

Personal incidents play a major role in any organisation because the workplace can potentially enhance family wellbeing and positive aspects of family life will spill over into the workplace; therefore, higher positive spill over between work and family, as reported in this study, has been associated with better self-appraised health and effects on an employee's psychological well-being at home and in the workplace. Goal achievement, Receiving recognition and Personal incidents are part of those aspects of the job that make people want to perform, and provide people with satisfaction; therefore, it is important. In order to understand people's behaviour at work, managers or supervisors must be aware of the concept of needs or motives, because this may lead to more positive emotion episodes in the workplace.

In the categories of negative emotion episodes, behaviour of work colleagues', acts of boss or superior or management and task requirement were reported most. All three reported categories may be the result of abuse of power in the workplace, such as workplace bullying, sexual harassment and narcissistic managers. Workplace bullying commonly occurs in organisations where dominant subordinate hierarchical relationships exist; therefore, it can lead to a destructive effect on the physical and mental health of the victim. Effective leadership is essential to the operation of the organisation and there is no place for narcissistic leaders who have an overpowering sense of self-importance, coupled with the need to be the centre of attention and who will often ignore the viewpoints of others within the organisation. Such behaviours harm the potential follower employees, as well as the organisation.

The overall conclusion can be made that organisations have many assets that contribute towards their success. One of the most important assets that any organisation can have is people. People are considered to be a valuable resource and that resource carries energy, which, in turn, creates productivity. For this resource to be fully captured and utilised, it is important for that resource to experience goal achievement and positive personal incidents so that well-being surrounds the individual's life at work and releases positive energy. When an unhappy or confrontational relationship exists between a manager or colleague and the employee, it will sap the energy from the precious resource and lead to negative emotions, non-performance and non-achievement contributing to the resultant unsuccessful organisation.

\section{Acknowledgement Competing interest}

The authors declare that they have no financial or personal relationship(s) which may have inappropriately influenced them in writing this article.

\section{Authors' contributions}

C.S.J. (North-West University) and A.vd.M. (North-West University) contributed equally to the writing of this article.

\section{References}

Ashkanasy, N. M. (2011). International Happiness: A multilevel perspective. Academy of Mangement Perspectives, February, 23-29. http://dx.doi.org/10.5465/ AMP.2011.59198446

Barnett, R.C., \& Hyde, J.S. (2001). Women, men, work, and family. American Psychologist, 56, 781-796.

Basch, J., \& Fisher, C. (1998). Affective events - emotions matrix: A classification of work events and associated emotions. School of Business Discussion Papers, Paper 65. Retrieved from http://epublications.bond.edu.au/discussion_papers/65

Basch, J., \& Fisher, C.D. (2000). Affective events - emotions matrix: A classification of work events and associated emotions. In N.M. Ashkanasy, C.E.J. Hartel, \& W.J. Zerbe (Eds.), Emotions in the workplace: Research, theory, and practice (pp. 3648). Westport, CT: Quorum Books.

Belschak, F.D., \& Den Hartog, D.N. (2009). Consequences of positive and negative feedback: The impact on emotions and extra-role behaviours. Applied Psychology: An International Review, 58(2), 274-303. http://dx.doi.org/10.1111/j.1464An International Revi
0597.2008.00336.x

Bialopotocki, R.N. (2007). Recognition and praise relate to teachers' job satisfaction. Doctoral dissertation. Nebraska-Lincoln: University of Nebraska-Lincoln.

Bitner, J.M., Booms, B.H., \& Tetreault, M.S. (1990). The service encounter: Diagnosing favourable and unfavourable incidents. Journal of Marketing, 54, 71-84. http:// dx.doi.org/10.2307/1252174

Blasé, J., \& Kirby, P. (1992). The power of praise: A strategy for effective principals. ASSP Bulletin, 76(548), 69-77. http://dx.doi.org/10.1177/019263659207654809

Bouckenooghe, D., Raja, U., \& Butt, A.N. (2013). Combined effects of positive and negative affectivity and job satisfaction on job performance and turnover intentions. The Journal of Psychology: Interdisciplinary and Applied, 147(2) intentions.

Bunk, J.A., \& Magley, V.T. (2013). The role of appraisals and emotions in understanding experiences of workplace incivility. Journal of Occupational Health Psychology, 18, 87-105.http://dx.doi.org/10.1037/a0030987, PMid:23339748

Census. (2011). Key results. Retrieved from http://statssa.gov.za

Chi, S., \& Liang, S. (2013). When do subordinates' emotion regulation strategies matter? Abusive supervision, subordinates' emotional exhaustion, and work withdrawal. The Leadership Quarterly, 24, 125-137. http://dx.doi.org/10.1016/j. withdrawal. The Leader

Cilliers, F. (2012). Leadership coaching experiences of clients with alexithymia. South African Journal of Industrial Psychology, 38(2), 1-10.

Dasborough, M.T. (2006). Cognitive asymmetry in employee emotional reactions to leadership behaviors. Leadership Quarterly, 17, 163-178. http://dx.doi. org/10.1016/j.leaqua.2005.12.004

Fisher, C.D. (2000). Mood and emotions while working: Missing pieces of job satisfaction. Journal of Organizational Behaviour, 21, 185-202. http://dx.doi org/10.1002/(SICI)1099-1379(200003)21:2\%3C185::AID-JOB34\%3E3.0.CO;2-M

Fisher, C.D., Minbashian, A., Beckmann, N., \& Wood, R.E. (2012). Task appraisals, emotions, and performance goal orientation. Journal of Applied Psychology. Retrieved from http://dx.doi.org/10.1037/a0031260

Frijda, N.H. (1987). Emotion, cognitive structure and action tendency. Cognition and Emotion, 1, 115-143. http://dx.doi.org/10.1080/02699938708408043

Frijda, N.H. (1988). The laws of emotion. American Psychologist, 43, 349-358. http:// dx.doi.org/10.1037/0003-066X.43.5.349, PMid:3389582

Gibson, D.E. (2006). Emotional episodes at work: An experiential exercise in feeling and expressing emotions. Journal of Management Education, 30, 477-500. http://dx.doi.org/10.1177/1052562905282016

Glaso, L., Vlie, T.L., Holmdal, G.R., \& Einarsen, S. (2011). An application of affective events theory to workplace bullying. European Psychologist, 16(3), 198-208. http://dx.doi.org/10.1027/1016-9040/a000026

Gooty, J., Connelly, S., Griffith, J., \& Gupta, A. (2010). Leadership, affect and emotions: A state of the science review. The Leadership Quarterly, 21, 979-1004. http:// dx.doi.org/10.1016/j.leaqua.2010.10.005

Gooty, J., Gavin, M., \& Ashkanasy, N.M. (2009). Emotions research in OB: The challenges that lie ahead. Journal of Organizational Behavior, 30, 833-838. http://dx.doi.org/10.1002/job.619

Gorgens-Ekermans, G.G., \& Brand, T. (2012). Emotional Intelligence as a moderator in the stress-burnout relationship: A questionnaire study on nurses. Journal of Clinical Nursing, 21, 2275-2285. http://dx.doi.org/10.1111/j.1365-2702.2012.04171.x, PMid:22788561 
Greenhaus, J.H., Allen, T.D., \& Spector, P.E. (2006). Health consequences of workfamily conflict: The dark side of the work-family interface. In P.L. Perrewe \& D.C. Ganster (Eds.), Research in Occupational Stress and Well-being, Vol. 5 (pp. 61-98). Ganster (Eds.), Research in Occup
Amsterdam: JAl Press/Elsevier.

Grzywacz, J.G. (2000). Work-family spill over and health during midlife: Is managing conflict everything? American Journal of Health Promotion, 14, 236-243. http:// dx.doi.org/10.4278/0890-1171-14.4.236, PMid:10915535

Haag, S. (2005). Annoyances in the workplace: An investigation of personality traits and interests. (Draft of 22 April). Retrieved from http://www.psychology.gatech. edu/KanferAckerman/sunnihaagseniorthesis.pdf

Half, R. (1994). Attracting the right employees and keeping them. Retrieved from http://www.workforce.com

Herzberg, F., Mausner, B., \& Snyderman, B.B. (1959). The motivation to work. New York: Wiley.

Hill, L.A. (1992). Becoming a manager: How new managers master the challenges of leadership. Cambridge, MA: Harvard Business School Press.

Hochschild, A.R. (1983). The managed heart: Commercialization of human feeling. Berkeley, CA: University of California Press.

Izard, C.E. (1991). Psychology of emotions. New York: Plenum.

Jones, F., \& Bright, J. (2001). Stress: Myth, theory and research. London: Prentice Hall.

Jonker, C.S., Van der Merwe, A.S., Fontaine, J.R., \& Meiring, D. (2011). The meaning of emotion in the white Afrikaans Language group: A componential emotion theory approach. Journal of Psychology in Africa, 21(4), 555-564.

Kafetsios, K., \& Zampetakis, L.A. (2008). Emotional Intelligence and job satisfaction: Testing the mediatory role of positive and negative affect at work. Personality and Individual Differences, 44, 712-722. http://dx.doi.org/10.1016/j.paid.2007.10.004

Kahnemann, D., Kreuger, A.B., Schkade, D.A., Schwartz, N., \& Stone, A.R. (2004). A survey method for characterising daily life experience: The day reconstruction method. Science, 306, 1776-1780. http://dx.doi.org/10.1126/science.1103572, PMid:15576620

Koortzen, P., \& Oosthuizen, R.M. (2012). Psychological experiences in South African society before the 2010 FIFA world cup from the systems psychodynamic and positive psychology perspectives. South African Journal of Industrial Psychology, 38(2), 1-13.

Lam, W., \& Cheng, Z. (2012). When I put on my service mask: Determinants and outcomes of emotional labour among hotel service providers according to the affective event theory. International Journal of Hospitality Management, 31 3-11. http://dx.doi.org/10.1016/j.ijhm.2011.04.009

Laplante, P. (2009). Requirements engineering for software and systems. Redmond, WA: CRC Press.

Li, Y., Ahlstrom, D., \& Ashkanasy, N.M. (2010). A Multilevel model of affect and organizational commitment. Asia Pacific Journal of Management, 27, 193-213. http://dx.doi.org/10.1007/s10490-010-9193-9

Lindenbaum, D., \& Jordan, D. (2012). Positive emotions, negative emotions or utility of discrete emotions? Journal of Organizational Behaviour, 33, 1027-1030. http://dx.doi.org/10.1002/job.1819

Lord, R.G., \& Kanfer, R. (2002). Emotions and organizational behavior. In R.G. Lord, R.J. Klimoski \& R. Kanfer (Eds.), Emotions in the workplace (pp. 5-19). San Francisco, CA: Jossey-Bass.

Makhuba, T.T. (2005). Bilingualism, language attitudes, language policy and language planning: A sociolinguistic perspective. Journal of Language and Learning, 3 , 268-278.

Malik, M.I., Saif, M.I., Gomez, S.F., Khan, N., \& Hussain, S. (2010) Balancing work and family through social support among working women in Pakistan. African Journal of Business Management, 4, 2864-2870.

Maslow, A., \& Lowery, R. (Ed.). (1998). Toward a psychology of being (3rd ed.). New York, NY: Wiley.
Meeusen, V., Van Dam, K., Van Zundert, A., \& Knape, J. (2010). Job satisfaction amongst Dutch nurse anaesthetists: The influence of emotions on events. Internationa Nursing Review, 57, 85-91. http://dx.doi.org/10.1111/j.1466-7657.2009.00763.x, Nursing Review,
PMid:20487479

Michel, J.S., \& Clark, M.A. (2009). Has it been affect all along? A test of work-tofamily and family-to-work models of conflict, enrichment, and satisfaction. Personality and Individual Differences, 47, 163-168. http://dx.doi.org/10.1016/j. paid.2009.02.015

Miles, M.B., \& Huberman, A.M. (1994). Qualitative data analysis. Thousand Oaks, CA: Sage.

Miner, A.G., Glomb, T.M., \& Hulin, C. (2005). Experience sampling mood and its correlates at work. Journal of Occupational and Organizational Psychology, 78, 171-193.http://dx.doi.org/10.1348/096317905X40105

Morgan, M., Ludlow, L., O'Leary, M., \& Clarke, A. (2010). What makes teachers tick? Sustaining events in new teachers's lives. British Educational Research Journal, 36(2), 191-208. http://dx.doi.org/10.1080/01411920902780972

Olckers, C., Buys, M.A., \& Grobler, S. (2010). Confirmatory factor analysis of the multidimensional emotional empathy scale in the South African context. SA Journal of Industrial Psychology, 36(1), Art. \#856, http://dx.doi.org/10.4102/sajip v361.856

Pintrich, P.R., \& Schunk, D.H. (1996). Motivation in education: Theory, research, and applications. Englewood Cliffs, NJ: Prentice Hall Merrill.

Russell, J.A. (1980). A circumplex model of affect. Journal of Personality and Social Psychology, 39, 1161-1178.

Sacco, R.G. (2010). The circumplex structure of depersonalization/derealization International Journal of Psychological Studies, 2(2), 26-40. http://dx.doi. org $/ 10.1037 / \mathrm{h} 0077714$

Salovey, P., \& Mayer, J.D. (1990). Emotional intelligence. Imagination, Cognition, and Personality, 9, 185-211.

Scherer, K.R. (2009). The dynamic architecture of emotion: Evidence for the component process model. Cognition and Emotion, 23(7), 1307-1351. http:// dx.doi.org/10.2190/DUGG-P24E-52WK-6CDG

Shikdar, A.A., \& Das, B. (2003). A strategy for improving worker satisfaction and job attitudes in a repetitive industrial task: Application of production standards and performance feedback. Ergonomics, 46, 466-481. http://dx.doi. org/10.1080/0014013021000057006

The languages of South Africa (n.d.). Retrieved from http://www.southafrica.info/ about/people/language.htm

The National Centre of Competence in Research, Affective Sciences (NCCR Affective Sciences) (n.d.). Retrieved from http://www.affective-sciences.org

Wegge, J., Van Dick, R., Fisher, G.K., West, M.A., \& Dawson, J.F. (2006). A test of basic assumptions of affective events theory (AET) in call centre work. British Journal of Management, 17, 237-254. http://dx.doi.org/10.1111/j.1467-8551.2006.00489.x

Weiss, H., \& Cropanzano, R. (1996). Affective events theory: A theoretical discussion of the structure, causes and consequences of affective experiences at work. Research in Organisational Behavior, 18, 1-79.

Westman, M., Brough, P., \& Kalliath, T. (2009). Expert commentary on work-life balance and crossover of emotions and experiences: theoretical and practical advancements. Journal of Organizational Behaviour, 30, 587-595. http://dx.doi. org/10.1002/job.616

Wright, T.A., \& Cropanzano, R. (1997). Wellbeing, satisfaction and job performance: Another look at the happy/productive worker thesis. Academy of Management Proceedings, 364-368.

Zerbe, W.J. (2008), Chapter 5: Feelings about ethical decisions: the emotions of mora residue, In W.J. Zerbe, C.E.J. Härtel \& N.M. Ashkanasy (Eds.), Emotions, Ethics and
Decision-Making (Research on Emotion in Organizations, Vol 4 (pp. 109-129). Decision-Making (Research on Emotion in Organizations, Vol 4 (pp. 109-129). 9791(08)04005-4 